\title{
Correlation among academic self-efficacy, professional identity, and professional attitude of higher vocational nursing students ${ }^{\dagger}$
}

Original article

Tian-Liang Xua , Jiang-Nan Zhao ${ }^{a}$, Yan-Yan Zhanga ${ }^{a}$ Gai-Li Jing ${ }^{\mathrm{b}, *}$

${ }^{a}$ Department of Nursing, Henan Medical College, Zhengzhou, Henan 450003, China

${ }^{b}$ Medical College, Zhengzhou University of Industry Technology, Zhengzhou, Henan 451150, China

Received: 12 July 2020; Accepted: 17 September 2020; Published: 20 March 2021

Abstract: Objective: To analyze the influence of professional identity and academic efficacy on the professional attitude of higher vocational nursing students.

Methods: A total of 656 higher vocational nursing students were investigated with general information questionnaire, academic self-efficacy scale, professional identity scale, and professional attitude scale of nursing students.

Results: The score of professional attitude of higher vocational nursing students was (106.34 \pm 9.86$)$, which is found to be in the upper middle level. The professional attitude of higher vocational nursing students is positively correlated with academic self-efficacy $(P<0.05)$, and with learning ability self-efficacy $(P<0.01)$. Professional cognition, professional will, and professional values have a positive predictive effect on the professional attitude of higher vocational nursing students $(P<0.05)$.

Conclusions: Academic self-efficacy and professional identity are important predictors of professional attitude. Learning behavior self-efficacy, professional cognition, professional will, and professional values have a significant impact on the establishment of positive professional attitude.

Keywords: vocational nursing students $\bullet$ professional attitude $\bullet$ academic self-efficacy $\bullet$ professional identity $\bullet$ correlation

(c) Shanxi Medical Periodical Press.

\section{Introduction}

Professional attitude is the individual's perception of a certain occupation and the psychological tendency to react in terms of behavior, which is the foundation of professional ethics. ${ }^{1}$ The International Medical Education Organization put forward that "professional attitude education of medical students should be listed first in the basic requirements of medical education." The State Council of China's Opinions on Deepening

† This project was supported by Humanities and Social Sciences Research of Henan Province (No. 2020-ZDJH-174) and Medical Education Research of Henan Province (No. wjlx2019221).

How to cite this article: Xu TL, Zhao JN, Zhang YY, Jing GL. Correlation among academic self-efficacy, professional identity, and professional attitude of higher vocational nursing students. Front Nurs. 2021;1:43-48. 
the Coordination of Medical Education and Further Promoting the Reform and Development of Medical Education once emphasized "to guide medical students to take prevention of diseases, relief of pain and the protection of the rights and interests of the public as professional responsibilities." ${ }^{2}$ Therefore, vocational attitude education has greater significance in improving the quality of medical personnel. As a reserve talent for nursing staff, nursing students must be cultivated for their correct and positive professional attitudes. As the many factors affect professional attitudes, Chinese studies generally believe that nurses have low professional recognition and high professional pressure. ${ }^{3}$ Foreign researchers have found that academic self-efficacy can affect the learning behavior, thinking and emotions of nursing students. ${ }^{4}$ However, there is little research on the professional attitudes of nursing students in higher vocational colleges based on academic self-efficacy and professional identity. So, in order to explore the influence of academic selfefficacy and professional identity on the professional attitude of vocational nursing students, the research team investigated the nursing students of 2 vocational colleges in Zhengzhou.

\section{Methods}

\subsection{Subjects}

A total of 656 nursing students from 2 vocational colleges in Zhengzhou were selected as research subjects using the convenient sampling method from September to November 2019. Inclusion criteria are: (1) Full-time students enrolled in nursing majors who have passed the national unified college entrance examination starting point of high school; and (2) Volunteer to participate in this research. Exclusion criteria are: transferred professionals and dropouts or leavers.

\subsection{Investigation method}

For conducting the on-site investigation by class, the questionnaires were issued in a unified way after obtaining the consent of the respondents. Before the survey, the researcher explained the purpose of the study and the principle of confidentiality to the respondents and applied the unified guidelines to guide the filling of the questionnaire, and collected the questionnaire on site. A total of 692 questionnaires were sent out and 656 effective questionnaires were recovered, with an effective rate of $94.79 \%$.

\subsection{Research tools}

\subsubsection{General information}

The research team consulted experts to design the questionnaire, which included gender, grade, source of birth, professional voluntary choice, academic performance, and education level of the main guardians.

\subsubsection{Nursing vocational students' professional identity scale}

The original nursing professional identity questionnaire was compiled by Hu Zhonghua ${ }^{5}$ and includes six dimensions: professional cognition, professional will, professional emotions, professional expectations, professional skills, and professional values. It was divided into 25 items based on Likert 5 grade to score, and the scores revealed that higher the score, the higher the professional recognition would be. Yin Yajuan ${ }^{6}$ team revised the original questionnaire according to the characteristics of the vocational nursing profession, and re-tested the reliability of the six dimensions of the revised scale. The test coefficient $r$ was between 0.72 and 0.87 . Both the validity of the questionnaire content and the consistency of the items were above 0.8 .

\subsubsection{Academic self-efficacy scale}

The scale was compiled by Liang Yusong ${ }^{7}$ based on the relevant questionnaires designed by Pintrich, ${ }^{8}$ and was divided into two dimensions of learning ability self-efficacy and learning behavior self-efficacy with a total of 22 items, using Likert 5 grade to score. The Cronbach's $\alpha$ coefficients of the scale and 2 dimensions were $0.872,0.820$, and 0.752 .

\subsubsection{Instrument of professional attitude for student nurses (I-PASN)}

The original scale was compiled by Hisar, ${ }^{9}$ and the translated Chinese version of I-PASN was done by Xiao Yuying. ${ }^{10}$ The scale contains 7 dimensions including professional development, cooperation, contribution to scientific knowledge, ethical standards and theories, nursing autonomy, community service and continuing education with a total of 28 entries; Using Likert 5 grade to score, and the higher the score, the more professional attitude would be. The total Cronbach's a coefficient of the scale was 0.868 , and the factor load of each item was between 0.409 and 0.838 . The extracted factors explain the $57.0 \%$ of the total variation and had good reliability and validity. 


\subsection{Statistical methods}

SPSS21.0 was used for $t$ test, $\chi^{2}$ test, and Pearson correlation analysis. The difference was considered statistically significant when $P<0.05$.

\section{Results}

\subsection{General information}

A total of 656 vocational nursing students participated-32 males and 624 females, aged 18-25 (21 \pm 2.76$)$ years; 289 aged 18-20 years and 367 aged 21-25 years. Sources of students: 455 in rural areas and 201 in urban areas; Professional voluntary selection method: 101 people choose independently, 419 parents or others will, 136 people transfer; Learning situation (average score):79 students: $\geq 85$ points, 241 students: $76-84$ points, 298 students: $60-75$ points, 38 students: $<60$ points; The education level of the main guardians: 177 people in junior high school and below, 397 people in high school or secondary school, and 82 people in college and above.

\subsection{The scores of academic self-efficacy, professional recognition, and professional attitude of nursing students}

The academic self-efficacy score of nursing students in higher vocational colleges was (75.27 \pm 9.27$)$, average score (3.42 \pm 0.61$)$, learning ability $(38.36 \pm 6.35)$, learning behavior $(36.91 \pm 5.64)$; The Professional recognition total score was (68.42 \pm 9.38$)$, average score (2.74 \pm 0.76$)$, professional recognition (14.29 \pm 3.20$)$, professional will (16.72 \pm 3.43$)$, professional emotion (14.17 \pm 2.39$)$, professional expect $(9.09 \pm 2.24)$, professional skills $(11.51 \pm 2.65)$, and professional values $(2.81 \pm 0.54)$. The professional attitude scores of higher vocational nursing students are shown in Table 1.

\subsection{Correlation analysis on professional attitude of vocational college nursing students, academic self-efficacy, and professional identity}

Professional attitude is positively correlated with academic self-efficacy and professional identity (Table 2).

\section{Discussion}

\subsection{The professional attitude of nursing students in higher vocational schools}

The results of the survey show that the total score of professional attitudes (106.34 \pm 10.86$)$ of nursing students in higher vocational schools is higher than the 70-point mark in the Hisar I-PASN scale, which is generally consistent with the results of Liang Huilian ${ }^{11}$ team. The highest score among the 7 dimensions is continuing education with an average score of (4.59 \pm 0.79$)$. Perhaps the current medical institutions need higher qualities for nursing talents, and vocational nursing students also recognize their deficiencies and look forward to continuing education to improve one's academic qualifications and abilities. The lowest score is community service. The reason may be that domestic community nursing started lately, and the hospitals where nursing students practiced have not involved the community field in practice, and so the vocational nursing students have not yet understood the community nursing. The survey found that ${ }^{12}$ vocational nursing students generally believe that community nursing work has low social recognition relatively, lack of development space, and poor welfare treatment, which indicate that vocational

\begin{tabular}{lcc}
\hline Dimension & Score & Item average \\
\hline \hline Professional attitude & $106.34 \pm 10.86$ & $3.79 \pm 0.85$ \\
Professional development & $23.12 \pm 3.77$ & $3.85 \pm 0.56$ \\
Cooperation & $17.89 \pm 3.52$ & $3.58 \pm 0.72$ \\
Contribution to & $20.92 \pm 3.90$ & $3.49 \pm 0.67$ \\
scientific knowledge & & \\
Ethical standards & $11.76 \pm 2.53$ & $3.92 \pm 0.72$ \\
and theories & & \\
Nursing autonomy & $12.48 \pm 2.31$ & $4.16 \pm 0.83$ \\
Community service & $6.39 \pm 1.38$ & $3.20 \pm 0.64$ \\
Continuing education & $13.78 \pm 2.47$ & $4.59 \pm 0.79$ \\
\hline
\end{tabular}

Table 1. The professional attitude scores of vocational nursing students $(N=656)$.

\begin{tabular}{lcc}
\hline Item & \multicolumn{2}{c}{ Professional attitude } \\
\cline { 2 - 3 } & $r$ & $P$ \\
\hline \hline Academic self-efficacy & & \\
Self efficacy of learning ability & 0.412 & 0.007 \\
Self efficacy of learning behavior & 0.245 & 0.042 \\
Total score & 0.323 & 0.025 \\
Professional identity & & \\
Professional cognition & 0.421 & 0.008 \\
Professional will & 0.428 & 0.006 \\
Professional emotions & 0.246 & 0.134 \\
Professional expectations & 0.152 & 0.048 \\
Professional skill & 0.261 & 0.206 \\
Professional values & 0.437 & 0.037 \\
Total score & 0.305 & 0.044 \\
\hline
\end{tabular}

Table 2. Correlation analysis on professional attitude, academic self-efficacy, and professional identity. 
nursing students lack necessary understanding of nursing work in the community and fail to recognize its development trend and prospects.

\subsection{The professional attitude of vocational nursing students is positively correlated with academic self-efficacy}

Academic self-efficacy refers to the individual's judgment and self-confidence in the ability to complete academic tasks. ${ }^{13}$ The performance of self-efficacy in the learning field and the degree of self-confidence that students use in their abilities or skills are used to complete learning tasks evaluation. The Ferla ${ }^{14}$ team research found that academic self-efficacy can predict important indicators of academic performance and can give students strong thinking and confidence. The results of the study show that the professional attitude of high vocational nursing students is positively correlated with academic self-efficacy $(P<0.05)$ and positively correlated with learning ability self-efficacy $(P<0.01)$, indicating that the stronger the academic self-efficacy of nursing students, the more professional positive attitude. Higher vocational nursing students' strong sense of academic self-efficacy can promote their positive professional attitude, and further, positive professional attitude will also promote the improvement of academic self-efficacy. ${ }^{15}$ Students with high-level learning ability and self-efficacy feel that they have the ability to complete learning tasks, and they can work hard and diligently when they encounter academic difficulties and frustrations. The Høigaard team found that learning ability self-efficacy can affect academics through psychological hint achievement. ${ }^{16}$ However, Palida's research believed that self-efficacy is related to professional attitudes. Academic self-efficacy does not significantly affect professional attitudes. ${ }^{17}$ The reason may be that the selected research subjects are from different regions and different ethnic groups, and nurses of different regions will have different views on professional attitudes. Further, the research team can try to expand the area and increase the sample size for future research.

\subsection{The professional attitude of professional nursing students is positively correlated with professional identity}

Professional identity is a dynamic concept that accompanies the learning process. It refers to the emotional acceptance and recognition of learners on the basis of cognitive understanding of the disciplines studied, together with positive external behaviors and inner appropriateness, a process of empathy, attitude and even cognition. ${ }^{18}$ The results of this study show that the professional attitude of professional nursing students is positively correlated with professional identity $(P<0.05)$. The higher the professional identity, the more positive the professional attitude will be. In all dimensions, professional cognition, professional will, professional expectations, and professional values can significantly affect the professional attitude of nursing students $(P<0.05)$. A high level of professional cognition is helpful to a high level of professional input, ${ }^{19}$ which can further promote a good professional attitude of nursing students, and an enhanced professional identity will further promote their motivation to learn professional knowledge and thus achieving a benign professional attitude and professional identity circulate which will promote each other. Kyung believes that the higher the professional interest of nursing students, ${ }^{20}$ the more positive the professional attitude. If the interest is not high, professionals will play a decisive role. Professional values can directly affect individual behavior and cognition, and also have a significant impact on their professional attitudes. Therefore, from the perspective of professional identification, medical teachers and teaching managers can adopt a variety of methods to integrate professional emotion and professional will in the teaching process, and gradually help nursing students to form a positive professional attitude through external factors.

\section{Conclusions}

The results of this study show that the professional attitude of vocational nursing students is at the upper middle level, and the awareness of community service needs to be improved. Academic self-efficacy and professional identity are important predictors of professional attitude. Self-efficacy of learning behavior, professional cognition, professional will, and professional values have a significant impact on the importance of establishing professional attitudes for vocational nursing students. Professional attitude is the foundation of professional ethics and takes a primary position in the process of optimizing the quality of nursing students. According to the actual situation of nursing students, nursing education practitioners should actively guide students to properly and objectively understand the majors they learn, strengthen professional will, enhance professional values, and finally cultivate their good professional attitudes.

\section{Ethical approval}

Ethical issues are not involved in this paper.

\section{Conflicts of interest}

All contributing authors declare no conflicts of interest. 


\section{References}

1. You XC, Zhou WX, Chang XB, et al. Preliminary construction of evaluation index system of professional attitude of intern nurses. J Nurs. 2016;31: 84-87 (in Chinese).

2. The State Council of the People's Republic of China. Opinions on deepening the collaboration between medical education and further advancing the reform and development of medical education; 2017-07-03. http://www.gov.cn/zhengce/ content/2017-07/11/content_5209661.htm (in Chinese). Accessed October 21, 2019.

3. Chen LM, Bian LF, Shao LF. Survey and countermeasures of nurses' job satisfaction in public hospitals. Chin J Hosp Adm. 2018;34:500-504 (in Chinese).

4. Bulfone G, Vellone E, Maurici M, Macale L, Alvaro R. Academic self-efficacy in Bachelorlevel nursing students: development and validation of a new instrument. J Adv Nurs. 2020;76: 398-408.

5. $\mathrm{Hu} \mathrm{ZH}$. Investigation and analysis of professional identity of undergraduate nursing students in Sichuan Province. Sichuan University; 2007 (in Chinese).

6. Yin YJ. Research on the status of professional identity and related factors of vocational nursing students in a college in Guangxi. Central South University; 2011 (in Chinese).

7. Liang YS. Research on the Goal of University Formation, Attribution Methods and Academic SelfEfficacy. Wuhan: Central China Normal University; 2000 (in Chinese).

8. Moliterni P, Stasio SD, Carboni M, et al. Motivational and self-regulated learning components of academic performance. EUCEN Conference 2010-Lifelone Learning for the New Decade; 2010.

9. Hisar F, AyiseKaradağ, Kan A. Development of an instrument to measure professional attitudes in nursing students in Turkey. Nurse Educ Today. 2010;30:726-730.

10. Xiao YY, Li T, Xiao L, et al. The Chinese version of Instrument of Professional Attitude for Student
Nurses (IPASN): assessment of reliability and validity. Nurse Educ Today. 2017;49:79-83.

11. Liang HL, Gao YL, Cai SL. Correlation analysis of professional attitude and academic self-efficacy of 1482 college nursing students. J Nurs. 2019;26: 53-56 (in Chinese).

12. $\mathrm{Pu} Y$, Huang RR, Tao L, Li L, Yu SY, Yang XN. Survey of patients' demand for clinical volunteer nursing services for nursing students. J Nurs. 2016;31:72-74 (in Chinese).

13. Liu XW, Ma X. The relationship between academic self-efficacy and student course satisfactionthe mediating role of student course experience. $J$ Beijing Univ Aeronaut Astronaut (Soc Sci Ed). 2015;28:116-120 (in Chinese).

14. Johan F, Martin V, Yonghong C. Academic selfefficacy and academic self- concept: reconsidering structural relationships. Learn Individ Differ. 2009;19:499-505.

15. Jun $\mathrm{WH}$, Lee $\mathrm{G}$. The mediating role of spirituality on professional values and self-efficacy: a study of senior nursing students. J Adv Nurs. 2016;72: 3060-3067.

16. Høigaard R, Kovač VB, Øverby NC, et al. Academic self-efficacy mediates the effects of school psychological climate on academic achievement. Sch Psychol Q. 2015;30:64-74.

17. Palida M, Shu JJ, Hu XM. Current status and influencing factors of occupational identity and selfefficacy of nursing students in Xinjiang area. Nurs Res. 2019;33:663-666 (in Chinese).

18. Sun AH, Li J, Tao YX, Zhang JQ, Xu XY. The correlation between clinical nurse professional identity and professional self-concept. Chin J Pract Nurs. 2016;4:241-245 (in Chinese).

19. Gao XY, Wang SS, An YQ, Chen Y. Research on the influence of undergraduate nursing students' professional identity and learning investment on the core competence of nursing students. Nurs Res. 2017;31:4074-4077 (in Chinese).

20. Kyung SB, Jeong HK, Myung HJ, et al. Professional values in Korean undergraduate nursing students. Nurse Edu Today. 2010;31:72-75. 